\title{
Conductive Hearing Loss in Autistic, Learning-Disabled, and Normal Children ${ }^{1}$
}

\author{
Donald E. P. Smith ${ }^{2}$ \\ University of Michigan \\ Samuel D. Miller \\ University of North Carolina at Greensboro \\ Michael Stewart \\ Michigan State University \\ Timothy L. Walter and James V. McConnell \\ University of Michigan
}

Katz (1978) has suggested that mild, fluctuating conductive hearing loss due to middle-ear anomalies may account for the language and attention problems of learning-disabled children. His position was extended here to include autism. Normal, learning-disabled, and autistic children received repeated impedance measures over 5 weeks. A repeated-measures ANOVA of central tendency and variablility values led to the conclusions that (1) fluctuating, negative middle-ear pressure greater than normal characterizes both autistic and learning-disabled children, (2) the negative pressure is greater in autistic than in learning-disabled children, and (3) the condition is typically bilateral for autistic children.

Several behavioral syndromes include attentional disorders as a defining characteristic: autism (Ornitz \& Ritvo, 1976; Smith, McConnell, Walter, \& Miller, 1985) learning disability (Battin, 1982; Routh, 1979), and hyperac-

'This research, project title "Language and Sensory Stimulation in Autistic Children," was made possible by a grant from the National Institutes of Mental Health (No. MH37035-02). ${ }^{2}$ Address all correspondence to Donald E. P. Smith, School of Education, Department of Educational Psychology, Room 1302, University of Michigan, Ann Arbor, Michigan 48109. 
tivity (Edelbrock, Costello, \& Kessler, 1984; Lahey, Schaughency; Strauss, \& Frame, 1984). Furthermore, while King \& Young (1982) and Lahey et al. (1984) have shown that DSM-III Attentional Deficit Disorder with and without hyperactivity are clearly different syndromes, Edelbrock et al. (1984) demonstrated that inattention is a dominant characteristic of both groups.

Smith et al. (1985) reported a severe attentional problem in 11 of 14 autistic children, ages 6 to 16, with only the oldest of the group able to maintain attention, as measured by Milburn's classification of Behavioral States (Konieczny \& Milburn, 1975; Konieczny, 1977). Furthermore, they reported significantly increased attention, increased signing, and reduced stereotypical behaviors in all except 1 of those children, coincident with use of augmented sound provided by an auditory trainer.

Katz (1978) has argued that a continued mild and fluctuating conductive hearing loss due to early and continuing middle-ear dysfunction may account for the attentional and language deficits of learning-disabled children. While there is increasing evidence of early middle-ear involvement in learning-disabled children (Holm \& Kunze, 1969; Needleman \& Menyuk, 1977; Masters \& Marsh, 1978), there is a dearth of empirical evidence on the incidence of serous and acute otitis media in autistic children. (Serous otitis media, abnormal fluid pressure in the middle ear, is detected by an impedance meter.) Gordon (1977) and Hayes and Gordon (1977) reported that, of 14 autistic children studied, 13 had fluctuating deafness and abnormally high acoustic reflex thresholds, while the last child had current middle-ear effusion (acute otitis media). Koegel and Schreibman (1976) have also reported fluctuating deafness in an autistic child.

If attention is related to conductive loss, and if attention is a problem for autistic and learning-disabled children, then one should find evidence of chronic and fluctuating middle-ear pressure in both learning-disabled and autistic children. Furthermore, the severity of the attentional problem should be related to the severity of the middle-ear problem in the order autistic $>$ learning-disabled $>$ normal.

\section{LITERATURE}

Speech and hearing specialists are in substantial agreement on the role of auditory conductance in language development. Both Downs (1981) and Battin (1982) have expressed concern about minimal conductive hearing losses in young children that are secondary to chronic otitis media. Downs cited Skinner's analysis of speech distortion resulting from reduction in auditory sensitivity and from fluctuating losses due to middle-ear dysfunction (Skinner, 1978). Numerous studies have appeared in the past 15 years 
documenting reduced language and school achievement of otherwise normal children with histories of recurrent serous or acute otitis media (Holm \& Kunze, 1969; Needleman \& Menyuk, 1977; Masters \& Marsh, 1978).

Whether attentional deficits may also be traced to early and chronic conductance disorders is at issue. Reduced capacity to respond to stimulation has been variously attributed to brain stem anomalies (Katz, 1978; see Ventry, 1980, for a critique), to vestibular disorders (deQuieros, 1976; see Keating, 1977, for a critique), and , more broadly, to telencephalic and/or brainstem and diencephalic structures (see Ornitz, 1985, for a review). Studies of conductance disorders may facilitate resolution of this issue.

Conductive hearing loss may result either from current acute otitis media or from residual middle ear blockage ("plugs' "; Katz, 1978) due to long-standing Eustachian tube anomalies. Blockage is inferred from the presence of pressure against the tympanic membrane, detected by impedance audiometry.

Despite the key symptom of a language deficit, both audiological and impedance studies of autistic children are rare. According to Koegel and Schreibman (1976) and to Hayes and Gordon (1977), autistic children usually do not receive thorough hearing examinations because of their disruptive behavior.

The present study was designed to determine, first, whether impedance measures will confirm the prediction of fluctuating conductive loss, and, second, whether the severity of the loss is related to the severity of the disorder, i.e., autistic > learning-disabled $>$ normal.

\section{METHOD}

\section{Subjects}

Subjects consisted of 50 children from three populations, as follows. Autistic. The autistic group comprised 8 of the 14 children described extensively in Smith et al. (1985) and 3 new referrals to a public developmental center in the Midwest. There were 8 males and 3 females, ranging in age from 45 months to 217 months, with a mean of 125.2 months (Table 1). The original group was shown to be typical of autistic children (Smith et al., 1985).

Learning-Disabled. Twenty learning-disabled children were drawn randomly from the population of third- and fifth-grade learning-disabled children in the same school district as the developmental center. There were 14 males and 6 females, ranging in age from 105 months to 150 months, with a mean of 124.8 months. The diagnosis of "specific learning disability" is defined by Michigan Special Education Rules (1980, R 340.1713 and 
Table I. Sex and Age of Children in a Study of Conductive Hearing Losses

\begin{tabular}{|c|c|c|c|c|c|}
\hline \multirow[b]{2}{*}{ Group } & \multirow[b]{2}{*}{$N$} & \multicolumn{2}{|c|}{ Gender } & \multicolumn{2}{|c|}{ Age (months) } \\
\hline & & $\bar{M}$ & $\bar{F}$ & $\vec{X}$ & $S D$ \\
\hline Normal & 19 & 9 & 10 & 122.2 & 13.9 \\
\hline $\mathrm{LD}^{\alpha}$ & 20 & 14 & 6 & 124.8 & 13.3 \\
\hline Autistic & 11 & 8 & 3 & 125.2 & 60.2 \\
\hline
\end{tabular}

LD $=$ learning-disabled.

requires "a severe discrepancy between achievement and intellectual ability" in defined skill areas, not attributed to sensory deficit, mental retardation, emotional disturbance, or environmental, cultural, or economic disadvantage, and must be determined by a multidisciplinary team, including a school psychologist.

Normal. Twenty normal children were drawn randomly from the same third- and fifth-grade classrooms as the learning-disabled children. One of these was found on examination to be suffering from acute otitis media and was unavailable for further testing. The 19 remaining included 9 males and 10 females, ranging in age from 84 months to 148 months, with a mean of 122.2 months.

\section{Procedure}

Impedance testing was carried out with a Teledyne Avionics impedance meter (TA-3D). Middle-ear compliance and pressure measurements were automatically recorded by an x-y plotter (Teledyne Avionics TA-3P). With certain exceptions due to absences, children were tested, by certified audiologists, at approximately the same time of day and on the same day of the week for 5 consecutive weeks or until five impedance scores were recorded for each child. There were no instances of refusal to cooperate and there was no difficulty with achieving an adequate seal in the external canal.

The impedance meter provides "an indirect measure of ... middle ear pressure by identifying the air pressure in the external canal at which the eardrum shows a peak of maximum compliance" (Northern \& Grimes, 1978 , p. 350). Middle-ear pressure values produce a curve showing change in sound pressure level in the ear canal as air pressure is varied from +200 $\mathrm{mm} \mathrm{H}_{2} \mathrm{O}$ to $-300 \mathrm{~mm} \mathrm{H}_{2} \mathrm{O}$. The point of maximum compliance of the tympanic membrane is that point at which the sound pressure introduced is equal to the pressure exerted from within. Normal pressure should be $0 \pm 25$ $\mathrm{mm} \mathrm{H}_{2} \mathrm{O}$ (Holmquist \& Miller, 1972; Feldman, 1975). Pressure values of $-100 \mathrm{H}_{2} \mathrm{O}$ or beyond indicate Eustachian tube malfunction (Feldman, 1975 , p. 371) and are considered sufficiently large for medical referral by 
Table II. Proportion (\%) of Normal and Abnormal Impedance Values for Three Diagnostic Groups of Children

\begin{tabular}{lccc}
\hline \multirow{2}{*}{ Impedance } & \multicolumn{3}{c}{ Group } \\
\cline { 2 - 4 } Values & Normal & LD $^{b}$ & Autistic \\
\hline Normal & 66 & 35 & 17 \\
Abnormal $^{a}$ & 34 & 65 & 83 \\
\hline
\end{tabular}

$a=>-25 \mathrm{~mm} \mathrm{H}_{2} \mathrm{O}$.

${ }^{b} \mathrm{LD}=$ learning-disabled.

some investigators (Cooper, Gates, Owen, \& Dicksen, 1976; McCandless \& Thomas, 1976). Other investigators recommend $-150 \mathrm{~mm}_{2} \mathrm{O}$ as a reason for close monitoring (Feldman, 1975, p. 364).

\section{RESULTS}

It was predicted that pressure values would differentiate normal children from learning-disabled children and learning-disabled from autistic children. It was also predicted that fluctuation in middle-ear pressure would be greatest for autistic followed by learning-disabled and normal children.

As a first estimate, we determined the distribution of "abnormal" pressure values, i.e., values greater than $0 \pm 25 \mathrm{~mm} \mathrm{H}_{2} \mathrm{O}$. Of the 250 tests given (5 each for 50 subjects), $107(43 \%)$ tests fell within $0 \pm 25 \mathrm{H}_{2} \mathrm{O}$ and $143(57 \%)$ fell outside that range. Table II shows the distribution of normal and abnormal values by group. Within the group of autistic children, $83 \%$ of the impedance values were greater than $-25 \mathrm{~mm} \mathrm{H}_{2} \mathrm{O}$ while, for normal children, $34 \%$ of the values were "abnormal," a ratio of 2.4 to 1.0 . A similar comparison for learning-disabled, $65 \%$ "abnormal," provides a ratio of 1.9 to 1.0. Table III indicates the incidence of children by group showing mean "abnormal" values (of five readings). Once more, normal children

Table III. Incidence of Children by Diagnostic Group with Abnormal Mean Impedance Values After Repeated Testing

\begin{tabular}{|c|c|c|c|c|c|c|}
\hline \multirow{3}{*}{$\begin{array}{l}\text { Impedance } \\
\text { Values }\end{array}$} & \multicolumn{6}{|c|}{ Group } \\
\hline & \multicolumn{2}{|c|}{ Normal } & \multicolumn{2}{|c|}{$\mathrm{LD}^{b}$} & \multicolumn{2}{|c|}{ Autistic } \\
\hline & $N$ & $\bar{X} \%$ & $N$ & $\bar{X} \%$ & $N$ & $\bar{X} \%$ \\
\hline $\begin{array}{l}\text { Normal } \\
\text { Abnormal }\end{array}$ & $\begin{array}{r}12 \\
7\end{array}$ & $\begin{array}{l}63 \\
37\end{array}$ & $\begin{array}{c}6 \\
14\end{array}$ & $\begin{array}{l}30 \\
70\end{array}$ & $\begin{array}{l}4 \\
7\end{array}$ & $\begin{array}{l}36 \\
64\end{array}$ \\
\hline
\end{tabular}

a $>-25 \mathrm{~mm} \mathrm{H}_{2} \mathrm{O}$.

${ }^{b} \mathrm{LD}=$ learning-disabled. 


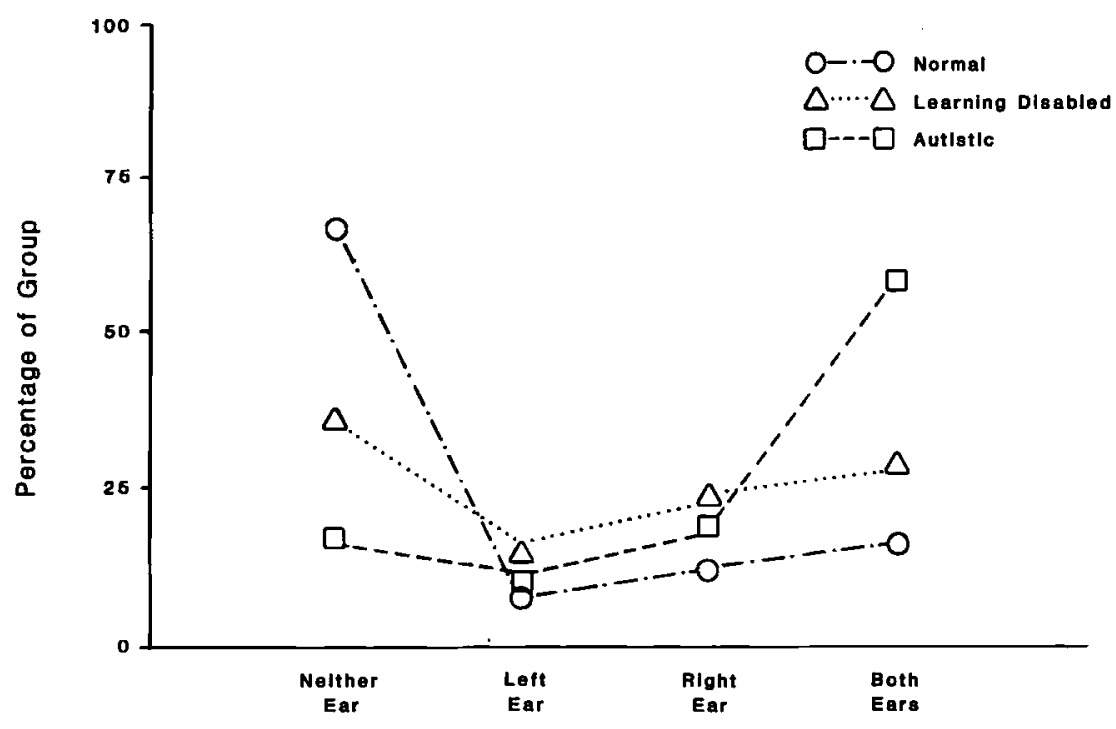

Abnormal Pressure

Fig. 1. Proportion of children in three diagnostic groups showing negative pressure beyond $-25 \mathrm{~mm} \mathrm{H}_{2} \mathrm{O}$ in neither ear, left ear only, right ear only, and both ears. $N \mathrm{~s}$ : autistic $=11$, learning-disabled $=20$, normal $=19$.

demonstrate primarily normal values $(63 \%)$ while both learning-disabled and autistic children show primarily "abnormal" values $(70 \%$ and $64 \%$, respectively).

Incidence by child by group was determined for right ear, left ear, both ears, and neither ear. Because of differing $N \mathrm{~s}$ in the groups, all summary data were reduced to percentages. Figure 1 displays the summary data by diagnostic category.

In general, normal children show primarily normal values $(66 \%$ within $0 \pm 25 \mathrm{~mm} \mathrm{H}_{2} \mathrm{O}$ ), autistic children show primarily other than normal values in both ears $(56 \%)$, and learning-disabled fall between these extremes.

Next we evaluated group data. While the impedance measure is quite accurate, it is sensitive to momentary changes owing to swallowing and other factors. To reduce the impact of outliers resulting from such changes, several measures of central tendency and of variability were computed with these data.

Results appear in Table IV for both ears (B), and for left (L) and right (R) ears independently. Analysis of variance with posthoc Scheffé tests of significance indicate differences as predicted both in central tendency and in variability. The negative pressure values of the autistic group are greater than those of normals both at the mean $(p=.001, .002$, and .008 , one- 


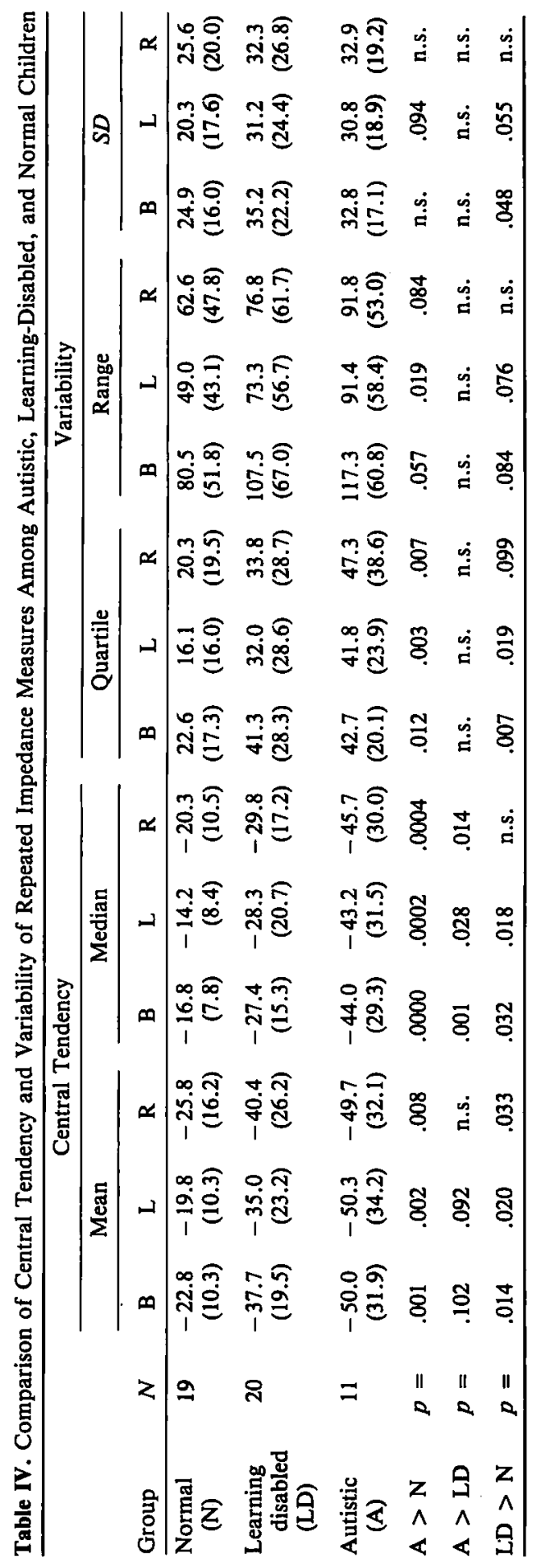


tailed) and at the median $(p=.0000, .0002$, and .0004$)$. The autistic group values are also greater than those of the learning-disabled group at the median $(p=.007, .028$, and .014$)$, though not at the mean. And learningdisabled values are greater than those of normals both at the mean $(p=$ $.014, .020$, and .033$)$ and at the median $(p=.032$ and .018$)$ except for the right ear.

Differences in pressure fluctuation may be estimated from three measures of variablility, the interquartile range, absolute range, and standard deviation. Autistic group values are greater than those of normals as estimated from the interquartile range $(p=.012, .003$, and .007). Learningdisabled values are also greater than normal by this criterion except for the right ear $(p=.007, .009$, and .099). However, learning-disabled and autistic groups do not differ in fluctuation. The other measures of variability, range and standard deviation, show only two differences, between autistic and normal on range for the left ear $(p=.019)$ and between learning-disabled and normal in standard deviation for the left ear, at a marginal level $(p=.055)$. The right ear-left ear differentials suggested that we should analyze our data further. Product-moment correlations were computed to test for independence of pressure values by right and left ears. Results, shown in Table V, indicated that right and left ear pressure values are significantly related for all three groups. However, the $r$ value for the autistic group (.661) is significantly higher than those of the learningdisabled (.405) and normal (.468) groups $(p=.02$ and .05 , respectively).

\section{DISCUSSION}

Conductive hearing losses due to middle ear anomalies, especially to chronic serous otitis media, may produce auditory deprivation with two kinds of effects: (1) direct, loss of high-frequency phonemes (e.g., $v, p, b$, $t h$ ), and (2) indirect, reduced stimulation of the auditory nerve. Katz (1978) has argued that the direct effect will result in variable distortion of language input and thus lead to some deficiencies in language. The indirect effect, by way of reduced stimulation of the brainstem, could lead to faulty cell development and thereby impair innervation of the cortex, leading to attentional deficits. The postulated indirect effect remains at issue.

However, Smith et al. (1985) found increased attentiveness and reduced sterotypic behaviors in autistic children coincident with increased auditory stimulation, and the elevated acoustic reflex thresholds of autistic children reported by Haynes and Gordon (1977) both suggest some relationship between conductance loss and attention.

If such a relationship obtains, one should find evidence of chronic and fluctuating middle-ear pressure in both learning-disabled and autistic 
children. Furthermore, the severity of the attentional problem should be related to the severity of the middle-ear problem in the order autistic > learning-disabled $>$ normal.

Such evidence is reported here. Repeated impedance testing of 50 children representing autistic, learning-disabled, and normal children showed autistic children to have elevated negative pressure $(\bar{X}=-50 \mathrm{~mm}$ $\left.\mathrm{H}_{2} \mathrm{O}\right)$ for both ears taken together, normals to have slight pressure $(\bar{X}=$ $-23 \mathrm{~mm} \mathrm{H}_{2} \mathrm{O}$, within the normal range of $0 \pm 25 \mathrm{~mm} \mathrm{H}_{2} \mathrm{O}$ ), and learningdisabled to be midway between those values $\left(\bar{X}=-37.7 \mathrm{~mm} \mathrm{H}_{2} \mathrm{O}\right)$. With certain interesting exceptions, both measures of central tendency, mean and median, showed the predicted differences. One exception was the difference between autistic and learning-disabled: The difference at the mean was only marginally significant (both ears, $p=.102$ ) while the difference at the median was significant $(p=.007)$.

Of three measures of variability (representing the postulated differences in fluctuation), the interquartile range showed both autistic and learning-disabled to differ from normals but not from each other. The standard deviation did not reliably differentiate the groups.

Correlation data provided two findings: (1) a strong tendency $(r=$ .661) among autistic children for involvement of both ears, and (2) no difference between normals and learning-disabled in the tendency for pressure in one ear to be predictive of pressure in the other ear. It is also of interest that the median and interquartile range were the more sensitive measures of central tendency and variability, suggesting that, as a diagnostic indicator, the range of values from repeated testings may be more useful than the mean value. Furthermore, it seems apparent from the data displayed in Figure 1 as well as from the ANOVA findings that autism tends to be a binaural phenomenon while learning disability tends to be a monaural phenomenon.

Finally, it is notable that the condition studied is serous otitis media rather than acute otitis media. The one potential subject identified in the acute (infected) stage was in the sample of normal children. No subject in the learning-disabled or autistic samples was so identified.

\section{CRITIQUE}

With the possible exception of Hayes and Gordon (1977), there appears to be no related study in the autism literature with which these findings may be compared. In fact, repeated measures of impedance as a method of assessment has not, to our knowledge, been reported.

Potential sources of error should be pointed out. Those include (1) identification of subjects, (2) possible measurement error in the impedance 
Table V. Relationship Between Repeated Impedance Values for Right Ear versus Left Ear for Autistic, Learning-Disabled, and Normal Children

\begin{tabular}{lcccc}
\hline \multicolumn{1}{c}{ Group } & $n$ & $r$ & $t$ & $p$ \\
\hline Normal & 19 & .468 & 5.10 & .0000 \\
LD & 20 & .405 & 4.37 & .0000 \\
Autistic & 11 & .661 & 6.42 & .0000 \\
$\begin{array}{l}\text { Autistic vs } \\
\quad \text { normal }\end{array}$ & & & & \\
$\quad \begin{array}{l}\text { Autistic vs } \\
\quad \text { LD }\end{array}$ & & & 1.65 & .05 \\
LD vs. & & & 2.13 & .02 \\
$\quad$ normal & & & .55 & n.s. \\
\hline
\end{tabular}

meter, (3) interpretation of impedance values, (4) possible influence of age differences, and (5) the tendency to infer causation.

1. We defined autistic children in a prior study (Smith et al., 1985) by accepting the criteria of a central diagnostic team followed by use of an instrument developed by Krug, Arick, and Almond (1980), the ASIEP scale. While there appears to be agreement on some of the behavioral symptoms of learning disability, there is wide variation in their use for labeling purposes both across and within states (Shepard, Smith, \& Vojir, 1983). In the present study, we accepted the judgment of the local school district, based upon state rules. However, learning-disabled subjects defined by other criteria might well yield data differing from ours.

2. and 3. As mentioned earlier, there are substantial differences in interpretation of impedance values among investigators and, probably, even more among practitioners. The audiologist who refers a child to a physician on the basis of repeated readings of $-200 \mathrm{~mm} \mathrm{H}_{2} \mathrm{O}$ may well be overruled by the physician who uses a visual examination only. While a visual examination may be sufficient to detect acute otitis media, impedance testing is usually necessary for detecting serous otitis media (Ginsberg \& White, 1978). The audiologist may hesitate to refer a child unless the impedance value is extreme. Problems such as this reflect the immaturity of this area of study and will be remedied only with experience.

4. It may be noted from Table I that, while mean age of the groups is equivalent, the standard deviation of the autistic group is four times that of the other groups. Since age differences in middle-ear pressure may exist, we determined the relationship between median pressure values and age. The $r$ of -.01 is not significant.

5. Finally, it must be pointed out that an hypothesis of a relationship between conductance loss and certain behavior disorders does not imply 
causality. While the two variables appear to be related, explanations other than causal abound: (a) Both may be caused by a third variable such as neural anomalies or chronic poor health; (b) inattention may be a side effect of the pain coincident with otitis media; (c) inattention may be a learned behavior, with the strength enhanced by chronic conductance loss.

However, we conclude that the potential sources of error discussed here do not seriously endanger the validity of the findings per se.

\section{CONCLUSIONS}

The following conclusions appear to be justified for the samples studied:

1. Both negative pressure and fluctuations in pressure in the middle ear greater than normal are typical of both autistic and learningdisabled children.

2. The negative pressure condition is more extreme for autistic children than for learning-disabled and is typically bilateral.

3. Learning-disabled children are differentiated from autistic children by degree of pressure and by single rather than bilateral involvement, but not by the degree of pressure fluctuation.

On the basis of the evidence presented here, we suggest that chronic conductive hearing loss in children with language and attentional disorders is a fruitful area of study and that the method of repeated impedance testing is an appropriate measure.

\section{REFERENCES}

Battin, R. R. (1982). Developmental effects of early middle ear disorders. Journal of the American Academy of Private Practice in Speech Pathology and Audiology, 4, 31-32.

Cooper, J., Gates, G., Owen, J., \& Dicksen, H. (1976). An abbreviated impedance bridge technique for school screening (pp. 373-379). In J. L. Northern (Ed.), Selected readings in impedance audiometry. New York: American Electromedics.

deQuieros, J. B. (1976). Diagnosis of vestibular disorders in the learning disabled. Journal of Learning Disabilities, 9, 37-50.

Downs, M. P. (1981). Amplification in the habilitation of the young deaf child. In G T. Mencher \& S. E. Gerber (Eds.), Early management of hearing loss (pp. 199-224). New York: Grune and Stratton.

Edelbrock, C., Costello, A. J., \& Kessler, M. (1984). Empirical corroboration of attention deficit disorder. Journal of the American Academy of Child Psychiatry, 23, 285-290.

Feldman, A. S. (1975). Acoustic impedance-admittance measurements. In L. J. Bradford (Ed.), Physiological measures of the audio-vestibular system. New York: Academic Press. 
Ginsberg, I. A., \& White, T. P. (1978). Otological considerations in audiology. In J. Katz (Ed.), Handbook of clinical audiology (2nd ed., Chap. 2). Baltimore: William \& Wilkins.

Gordon, A. G. (1977). Fluctuating deafness and autism. Journal of Autism and Developmental Disorders, 7, 115-116.

Hayes, R. W., \& Gordon, A. G., (1977). Auditory abnormalities in autistic children, Lancet, $2,767$.

Holm, V. A., \& Kunze, L. V. H. (1969). Effect of chronic otitis media on language and speech development. Pediatrics, 13, 833-839.

Holmquist, J., \& Miller, J. (1972). Eustachian tube evaluation using the impedance bridge. Mayo Foundation Impedance Symposium (pp. 297-307). Rochester, Minnesota: Mayo Foundation.

Katz, J. (1978). The effects of conductive hearing loss on auditory function. Journal of the American Speech and Hearing Association, 20, 879-886.

Keating, C. L. (1977). The relationship between the vestibular system, dyslexia, and reading in a selected population: A clinical study. Unpublished doctoral dissertation, University of Michigan.

King, C., \& Young, R. D. (1982). Attentional deficits with and without hyperactivity: Teacher and peer perceptions. Journal of Abnormal Child Psychology, 10, 483-496.

Koegel, K. L., \& Schreibman, L. (1976). Identification of consistent responding to auditory stimuli by a functionally "deaf" autistic child. Journal of Autism and Childhood Schizophrenia, 6, 147-156.

Konieczny, B. J. (1977). Physiological correlations between the auropalpebral reflex, cardiac rate and arbitrarily defined behavioral states in autistic children. Unpublished manuscript, University of Michigan.

Konieczny, B. J., \& Milburn, W. O. (1975). Behavioral states observed in non-symbolic language of children with autistic symptoms. Unpublished manuscript, University of Michigan.

Krug, D. A., Arick, J. R., \& Almond, P. A. (1980).Autism screening instrument for educational planning. Portland, Oregon: ASIEP Educational Co.

Lahey, B. B., Schaughency, E. A., Strauss, C. C., \& Frame, C. L. (1984). Are attention deficit disorders with and without hyperactivity similar or dissimilar disorders? Journal of the American Academy of Child Psychiatry, 23, 302-309.

Masters, L., \& Marsh, G. E. (1978). Middle ear pathology as a factor in learning disabilities. Journal of Learning Disabilities, 11, 54-57.

McCandless, G., \& Thomas, G. (1976). Impedance audiometry as a screening procedure for middle ear disease. In J. L. Northern (Ed.), Selected readings in impedance audiometry (pp. 369-372). New York: American Electromedics.

Michigan Special Education Rules. (1980). Lansing, Michigan: Michigan State Board of Education.

Needleman, H., \& Menyuk, P. (1977). Effects of hearing loss from early recurrent otitis media on speech and language development. In B. Jaffe (Ed.), Hearing loss in children (Chap. 44). Baltimore: University Park Press.

Northern, J. L., \& Grimes, A. M. (1978). Introduction to acoustic impedance. In J. Katz (Ed.), Handbook of clinical audiology (2nd ed., Chap. 29). Baltimore: William \& Wilkins

Ornitz, E. W. (1985). Neurophysiology of infantile autism. Journal of the American Academy of Child Psychiatry, 24, 251-262.

Ornitz, E. W., \& Ritvo, E. R. (1976). The symdrome of autism: A critical review. American Journal of Psychiatry, 133, 609-621.

Routh, D. K. (1979). Activity, attention and aggression in learning disabled children. Journal of Clinical Child Psychology, 8, 183-187.

Shepard, L., Smith, M., \& Vojir, C. (1983). Characteristics of pupils identified as learning disabled. American Educational Research Journal, 20, 309-331.

Skinner, M. W. (1978). The hearing of speech during language acquistition. Otolaryngological Clinics of North America, 11, 631-650. 
Smith, D. E. P., McConnell, J. V., Walter, T. L., \& Miller, S. D. (1985). The effect of using an auditory trainer on the attentional, language, and social behaviors of autistic children. Journal of Autism and Developmental Disorders, 15, 285-302.

Ventry, I. M. (1980). Effects of conductive hearing loss: Fact or fiction. Journal of Speech and Hearing Disorders, 45, 143-156. 